\title{
Diagnosis of Active Groups of Samples Taken (Aniline-Benzoic Acid -Acetic Anhydride and Comparing: The Results of the Laboratory)
}

\author{
Allaa Hussein Mhdi Salh Al-amiri \\ Correspondence: M.Sc. in Analytical Chemistry, Department of Chemistry, College of Science, University of Diyala, \\ Baqubah, Diyala, Traq. Email: Allaa.hussein@yahoo.com
}

Received: November 18, 2015 Accepted: December 7, 2015 Online Published: April 15, 2016

doi:10.5539/ijc.v8n2p51

URL: http://dx.doi.org/10.5539/ijc.v8n2p51

\begin{abstract}
FTIR comparison study between experimental and computational calculations by four molecular modeling methods (AM1, PM3, HF and DFT) was carried out to identify the vibration frequencies of different bonds for some compounds such as benzoic acid, aniline and phthalic anhydride to evaluate the accuracy of each method and to determine the shift value of frequencies for each bond. Results obtained confirm that the accuracy depends on the type of method and the functional group present near the certain bond.
\end{abstract}

Keywords: Semi-empirical methods, AM1, PM3, HF, DFT Vibration modes

\section{Introduction}

Computational chemistry uses the results of theoretical chemistry. Incorporated into efficient computer programs to calculate the structure and properties of molecules. It's based on theories which range from highly accurate suitable for small system and very approximate sutable for large systems. Semi-empirical, ab initio, Hartree fock (HF) and density functional theory (DFT) methods were used to determine which results match the experimental geometry.

Austin Model 1 (AM1) by Dewar and co-workers, takes in approximating two-electron integrals and uses a modified expression for nuclear-nuclear core repulsion.

Parametric Method 3 (PM3) by James Stewart, uses a Hamiltonian is very similar to the AM1 Hamiltonian but the parameterization strategy is different. AM1 was parameterized largely based on a small number of atomic data, PM3 is parameterized to reproduce a large number of molecular properties. Chemistry gave way to statistics with the PM3 model .Hartree-Fock theory (HF) is a single electron approximation technique used in multi electron systems. The molecular Hamiltonian is split up into individual single electron Hamiltonians. Consider a molecular system with N-electrons, each with degrees of freedom (ANIS. A. Et. Al. 1992, Harrison .N. et .al., 2002 and Donald W et.al, 2003 ).

Density Functional Theory (DFT) is a computational method derives properties of the molecule based on a determination of the electron density of the molecule. Unlike the wave function, which is not a physical reality but a mathematical construct, electron density is a physical characteristic of all molecules. DFT is a function of a function, and the energy of the molecule is a functional of the electron density. The electron density is a function with three variables $\mathrm{x}-$, y-, and z-position of the electrons (Christopher .J .et al., 2004).

\section{Calculation Methods}

Semi Empirical Quantum Mechanical Calculations (AM1 and PM3) were used, Hartree fock (HF) and Density Functional Theory (DFT) also was used at-B3LYP-3-21G and B3LYP 6-31G basis sets to estimate the IR value for Benzoic acid, Aniline and phthalic Anhydride ( Marcus et.al., 2001).

\section{Experimental}

Pure sample of benzoic acid, phthalic anhydride were used in analytical lab grade while experimental FTIR spectrum of aniline was extracted from). The FT-IR spectrum of these compounds were recorded at central research in chemistry department at college of science in diyala university, spectrophotometer equipped with DTGS detector and XT-KBr beam splitter (Peeter. I., 2005).

\section{Result and Discussion}

The FTIR spectrum of benzoic acid fig (1) is shown in fig (2) the vibrational spectra experimental values. Experimental and theoretical IR values are listed in Table-1. 


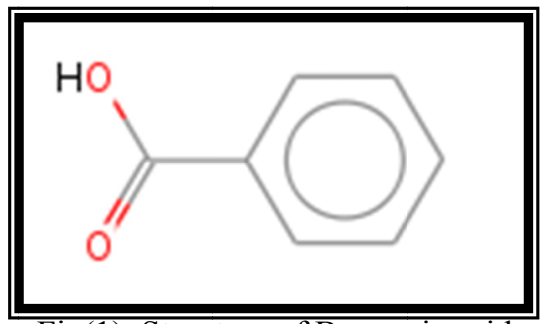

Fig(1). Structure of Benzouic acid

For $\mathrm{C}==\mathrm{O}$ str., $\mathrm{PM} 3$ method was found the nearest method from the experimental with shift about $40 \mathrm{~cm}^{-1}$. While for $\mathrm{C}-\mathrm{O}$ str., $\mathrm{PM} 3$ method still the best one relative to the experimental value obtained. In the case of $\mathrm{O}-\mathrm{H}$ str. And $\mathrm{O}-\mathrm{H}$ bend there is a degree of acceptability for AM1.

Table (1). Experimental and theoretical IR data of benzoic acid

\begin{tabular}{|c|c|c|c|c|c|c|c|c|}
\hline bond & AM1 & INDO & PM3 & HF-3-21G & $\begin{array}{l}\text { DFT- } \\
\text { B3LYP-3-21 } \\
\text { G }\end{array}$ & $\begin{array}{l}\text { DFT- } \\
\text { B3LYP } \\
\text { 6-31G }\end{array}$ & Exp. & $\begin{array}{l}\text { Best shift } \\
\left(\mathrm{cm}^{-1}\right)\end{array}$ \\
\hline $\mathrm{C}==\mathrm{O}$ str. & 1917 & 2811 & 1724 & 1746 & 1558 & 1583 & 1683.66 & $\begin{array}{l}\text { PM3 } \\
+40.34\end{array}$ \\
\hline $\mathrm{C}-\mathrm{O}$ str. & 1206 & 2393 & 1133 & 1131 & 927 & 959 & 1086 & $\begin{array}{l}\text { PM3 } \\
+55\end{array}$ \\
\hline $\mathrm{O}-\mathrm{H}$ str. & 3520 & 5373 & 3758 & 3795 & 3942 & 3904 & 3567 & $\mathrm{AM} 1+47$ \\
\hline O---H bend. & 1413 & 1127 & 1326 & 1267 & 1247 & 1259 & 11791169 & $\begin{array}{l}\text { AM! } \\
+48 \\
\end{array}$ \\
\hline
\end{tabular}

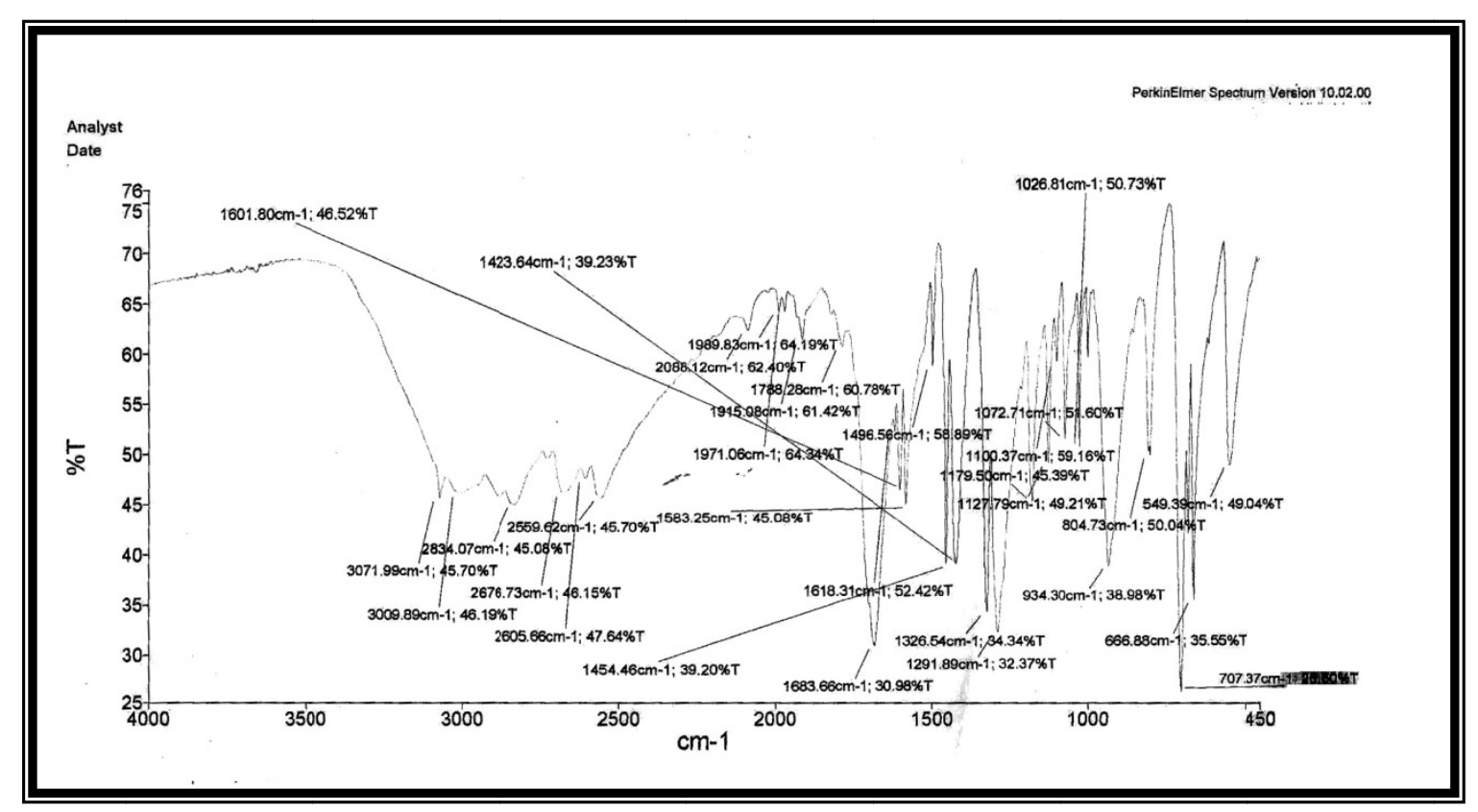

Fig (2). Vibrational spectra of benzoic acid experimental value 


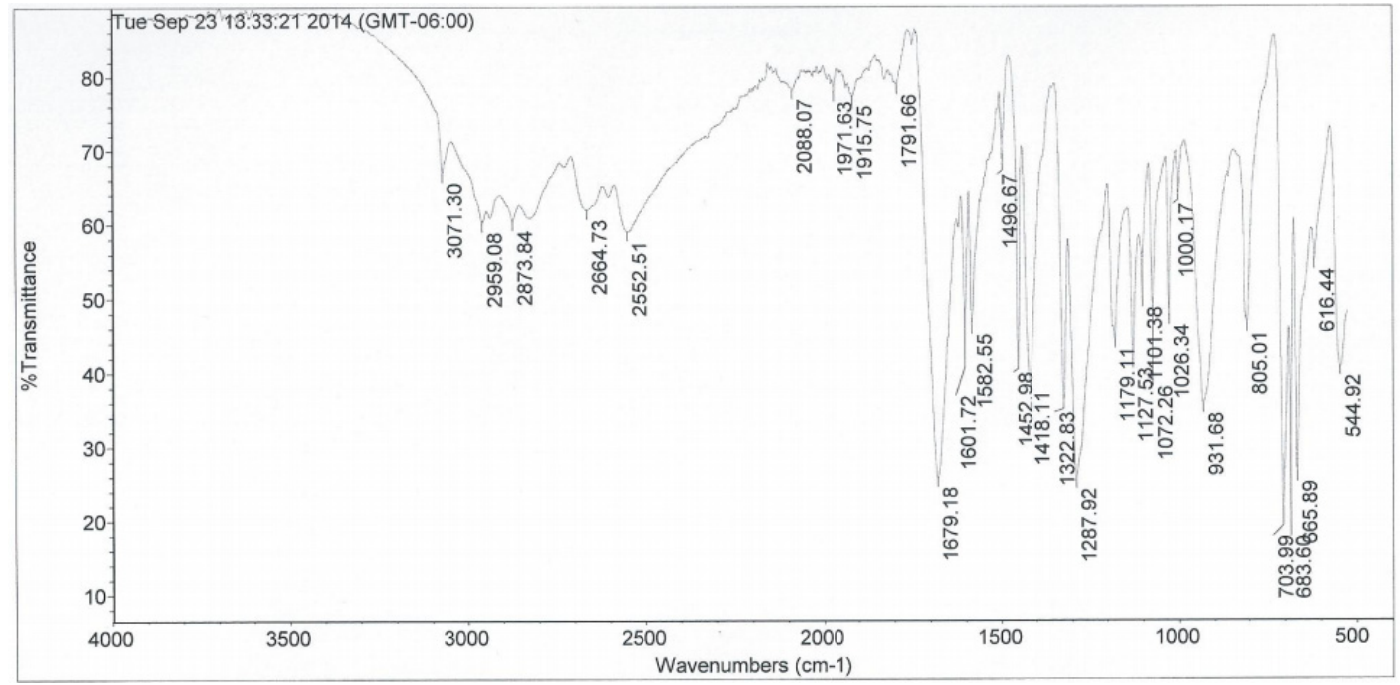

Fig(3). Vibrational spectra for benzoic acid

Experimental FT-IR spectrum of aniline is shown in table (2), it is clearly seen that AM1 method is more likely to give slightly shift compared to the other metods for ( $\mathrm{N}-\mathrm{H}$ str. Sy ) while for $\mathrm{N}-\mathrm{H}$ str. asy and $\mathrm{N}-\mathrm{H}$ bend PM3 method was observed the minimum shift. For C-N str. DFT-B3LYP-3-21G being the MOST value closer one in spite of that the shift is far to some extent .

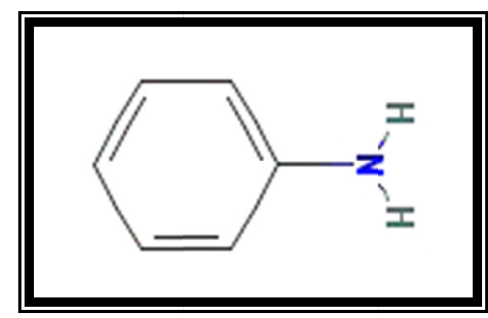

Fig (4). Structure of Aniline

Table (2). Experimental and theoretical IR data of aniline

\begin{tabular}{|c|c|c|c|c|c|c|c|c|}
\hline bond & AM1 & PM3 & HF-3-21G & INDO & $\begin{array}{l}\text { DFT } \\
\text { B3LYP-3-21G }\end{array}$ & $\begin{array}{l}\text { DFT } \\
\text { B3LYP } \\
6-31 G\end{array}$ & $-\quad$ Exp. & Best shift \\
\hline $\mathrm{N}-\mathrm{H}$ str. sy & 3462 & 3502 & 3730 & 5950 & 3559 & 3693 & 3442 & AM1 +20 \\
\hline $\mathrm{N}-\mathrm{H}$ str. asy & 3422 & 3369 & 3820 & 6016 & 3675 & 3805 & 3360 & PM3 +9 \\
\hline $\mathrm{N}-\mathrm{H}$ bend. & 1686 & 1642 & 1818 & 1108 & 1696 & 1653 & 1619 & PM3 +23 \\
\hline $\mathrm{C}-\mathrm{N}$ str. & 1368 & 1144 & 1201 & 1589 & 1344 & 1140 & 1281 & $\begin{array}{l}\text { (DFT- } \\
\text { B3LYP-3-21G) } \\
+63\end{array}$ \\
\hline
\end{tabular}

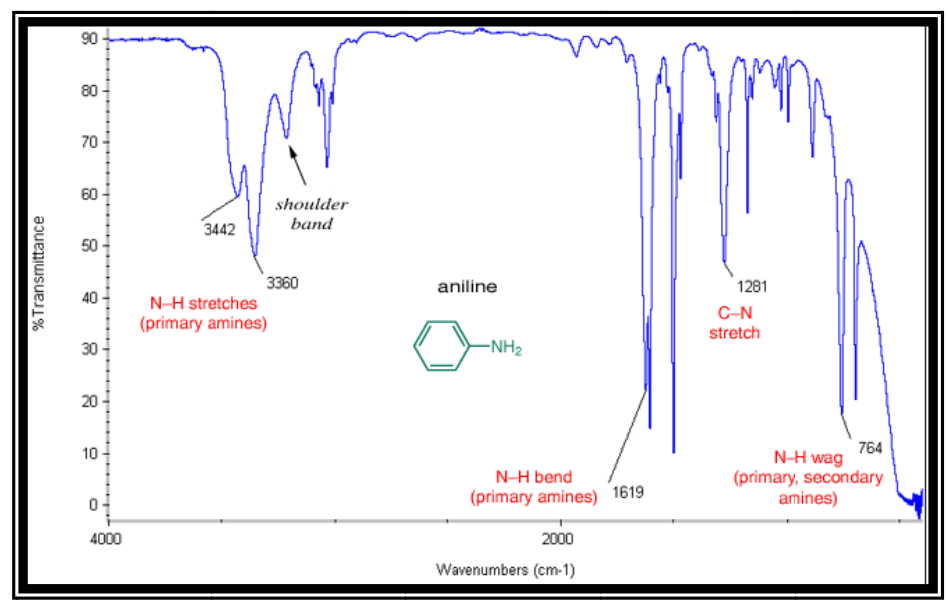

Fig(5). Vibrational spectra for Aniline 
In Phthalic anhydride fig(6), the $v \mathrm{C}=\mathrm{O}$ band is split into 2 peaks, the peaks in fig(7) shows data for $(\mathrm{C}==\mathrm{O}$ str. Sy , $\mathrm{C}==\mathrm{O}$ str. Asy, $\mathrm{C}-\mathrm{O}, \mathrm{C}-\mathrm{H}$ str. Sy. and after calculations this data obey (DFT $-\mathrm{B} 3 \mathrm{LYP}-3-21 \mathrm{G})$ model .

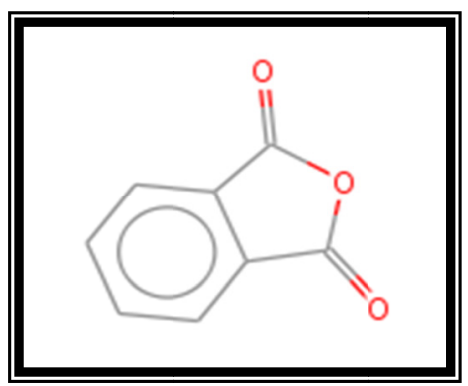

Fig(6). Structure of phthalic anhydride

Table (3). Experimental and theoretical IR data for phthalic anhydride

\begin{tabular}{|c|c|c|c|c|c|c|c|c|}
\hline bond & AM1 & PM3 & INDO & $\mathrm{HF}$ & $\begin{array}{c}\text { DFT- } \\
\text { B3LYP-3-21G }\end{array}$ & $\begin{array}{c}\text { DFT- } \\
\text { B3LYP6-31G }\end{array}$ & Exp. & Best shift \\
\hline $\mathrm{C}==\mathrm{O}$ str. sy & 1957 & 1754 & 2854 & 1667 & 1881 & 1879 & $\begin{array}{l}1791.09 \\
1789^{(16)}\end{array}$ & PM3 -37 \\
\hline $\mathrm{C}==\mathrm{O}$ str. asy & 1878 & 1672 & 2817 & 1558 & 1815 & 1817 & 1762.29 & $\begin{array}{c}(\mathrm{DFT}-\mathrm{B} 3 \mathrm{LYP}-3-21 \mathrm{G}) \\
+52.11\end{array}$ \\
\hline C--O & 1213 & 1156 & 1742 & 1154 & 1094 & 1097 & 1071.46 & $\begin{array}{c}(\mathrm{DFT}-\mathrm{B} 3 \mathrm{LYP}-3-21 \mathrm{G}) \\
+22.54\end{array}$ \\
\hline
\end{tabular}
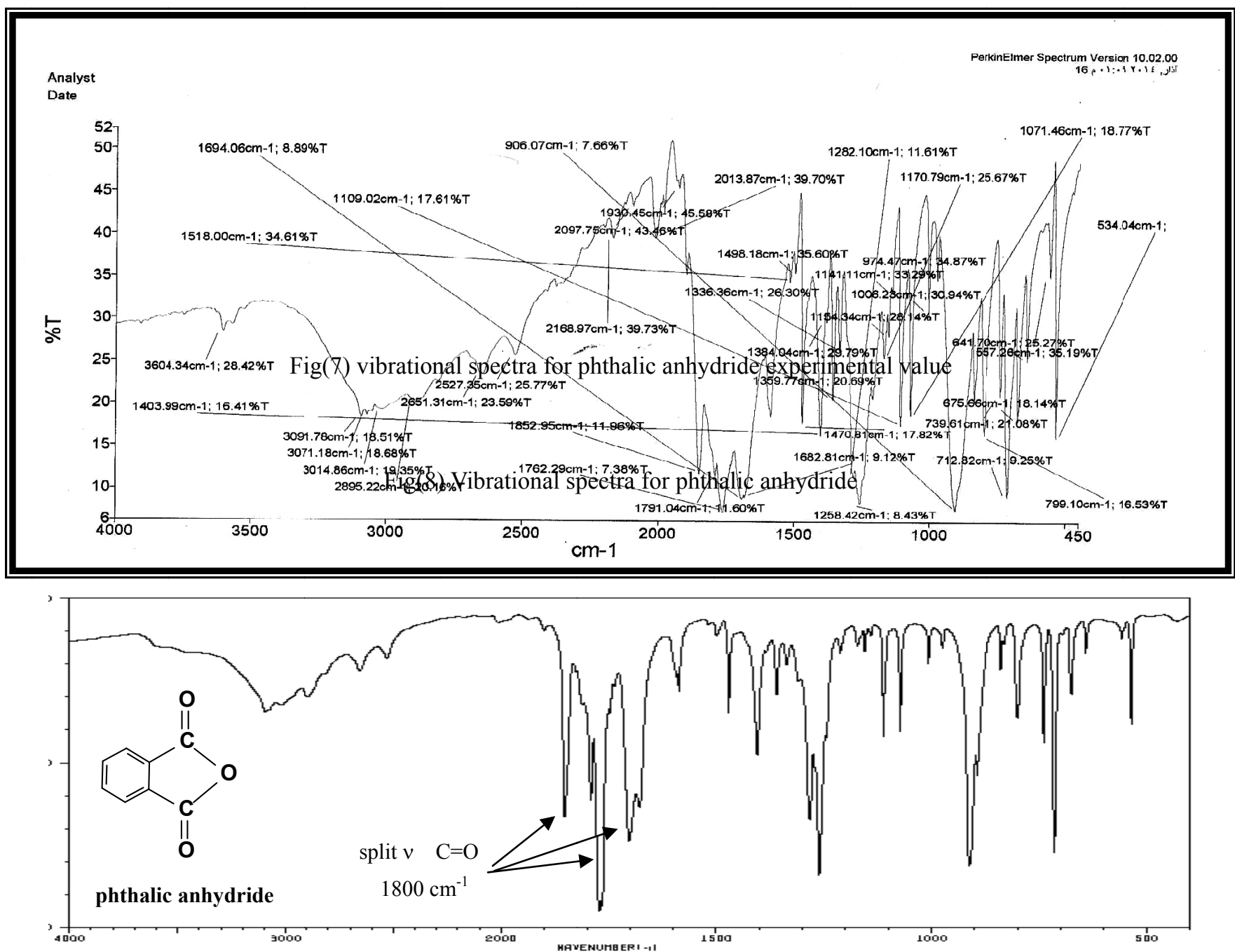

As shown in table-3, for $\mathrm{C}==\mathrm{O}$ str. sy, $\mathrm{PM} 3$ method is still the best one relative to the others as observed for the same 
bond in benzoic acid while asy carbonyl bond do not obey this rule and DFT is agree something to the experimental results (Seshadri.S.2007, Gilles. F., 2008, Denis. V., 2010, Salah. A., 2011, Adejoro. I., 2012, Cleydson, B., 2013, Salah, A., 2014 and Parmar, A., 2015).

\section{Conclusion}

Several organic compounds (benzoic acid, Aniline and phathalic Anhydride) have been studied using experimental and theoretical methods to determine the infrared frequencies of the main functional groups. Results show that PM3 and AM1 methods represent the best model for calculate the mentioned groups.

\section{References}

Adejoro, I. A., Oyeneyin, O. E., \& Adeboye, O. J. A. (2012). PM3 Semi Empirical Quantum Mechanical Calculations on a Novel Dichlorobis (N-\{4-[(2-pyrimidinyl-kN-amino)sulfonyl $\}$ acetamide]copper(II) Containing a Metabolite $\mathrm{N}$-acetylsulfadiazine, Journal of Computational Methods in Molecular Design, 2(4),142-148.

Anis, M. A. (1992). ABC Infrared, Iraq.

Christopher, J. C. (2004). Essentials of Computational Chemistry, Second Edition, Department of Chemistry and Supercomputing Institute, University of Minnesota, USA.

Cleydson, B. R. D. S., Cleison, C. L., Josinete, B. V., Davi, S. B. B., Alaan, U. B., Williams, J. C. M., José, C. T. C., \& José, C. P. (2013). Evaluation of Quantum Chemical Methods and Basis Sets Applied in the Molecular Modeling of Artemisinin,Computational Molecular Bioscience, 3, 66-79. http://dx.doi.org/10.4236/cmb.2013.33009

Denis, V. C., \& Oleg, V. M. (2010). DFT B3LYP Quantum-Chemical Calculation of Molecular Structures of (6.6.6)Macrotricyclic MII Complexes with (N,N,N,N)-Coordinating Ligand Formed in the MIIHydrazinomethanethiohydrazide Propanone Triple Systems, Mакрогетероцикль /Macroheterocycles, 3(2-3) 171-175, Russia. http://Macroheterocycles.isuct.ru.

Donald, W. R. (2003). Computational Chemistry Using the PC, Third Edition, Canada

Gilles, F., \& Gilles, O. (2008). A comparative study of semiempirical, ab initio and DFT methods in evaluating metal-ligand bond strength, proton affinity and interactions between 1st and 2nd shell ligands in Zn-biomimetic complexes, Journal of Computational Chemistry, 29, 416-433. http://dx.doi.org/10.1002/jcc.20800

Harrison. N. M. (2002). An Introduction to Density Functional Theory, Department of Chemistry, Imperial College of Science Technology and Medicine, SW7 2AY, London and CLRC, Daresbury Laboratory, Daresbury, Warrington, WA4 4AD.

Marcus, E., Karl, J., Jalkanen, M. K. M., Thomas, F., \& Sandor, S. (2001). Energetics and structure of glycine and alanine based model peptides: Approximate SCC-DFTB, AM1 and PM3 methods in comparison with DFT, HF and MP2 calculations, M. Elstner et al. / Chemical Physics, 263, 203-219. www.elsevier.nl/locate/chemphys.

Parmar, A., \& Arora, K. (2015). Vibrational Spectroscopic Studies of Schiff base compounds derived from 4 Amino Antipyrine by Quantum chemical investigations, Research Journal of Chemical Sciences, 5(9), 49-59.

Peeter, B., Imbi, R., \& Tarmo, T. (2005). Comparative semiempirical, ab initio, and DFT study of interactions between polypyrrole pentamer dication and some anions, Proc. Estonian Acad. Sci. Chem., 54(2), 85-93.

Salah, A. J. H. (2011). Homo-Lumo, Irfrared Frequencies and Molecular Geometry Comparsion Study pf the Strength of Boron. Trihalides Acidity Using Am1 Molecular Modeling, Iraqi journal of science, 52(2), 135-139.

Salah, A. J. H. (2014). Determination of Relative Reactivity of HSAB Complexes Using DFT Theory, Iraqi Journal of Science, 55(2B), 617-622.

Seshadri, S., Gunasekaran, S., Muthu, S., Kumaresan, S., \& Arunbalaji, R. (2007). Vibrational spectroscopy investigation using ab initio and density functional theory on flucytosine, Journal of Raman Spectroscopy, 38(11), 1523-1531. http://dx.doi.org/10.1002/jrs. 1808

\section{Copyrights}

Copyright for this article is retained by the author(s), with first publication rights granted to the journal.

This is an open-access article distributed under the terms and conditions of the Creative Commons Attribution license (http://creativecommons.org/licenses/by/3.0/). 